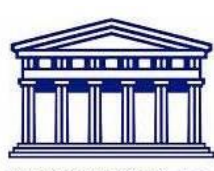

UNIVERSITY of the WESTERN CAPE

\title{
Enhanced performance of polybenzimidazole-based high temperature proton exchange membrane fuel cell with gas diffusion electrodes prepared by automatic catalyst spraying under irradiation technique
}

Huaneng Su, Sivakumar Pasupathi, Bernard Jan Bladergroen, Vladimir Linkov and Bruno G. Pollet

\begin{abstract}
Gas diffusion electrodes (GDEs) prepared by a novel automatic catalyst spraying under irradiation (ACSUI) technique are investigated for improving the performance of phosphoric acid (PA)-doped polybenzimidazole (PBI) high temperature proton exchange membrane fuel cell (PEMFC). The physical properties of the GDEs are characterized by pore size distribution and scanning electron microscopy (SEM). The electrochemical properties of the membrane electrode assembly (MEA) with the GDEs are evaluated and analyzed by polarization curve, cyclic voltammetry (CV) and electrochemistry impedance spectroscopy (EIS). Effects of PTFE binder content, PA impregnation and heat treatment on the GDEs are investigated to determine the optimum performance of the single cell. At ambient pressure and $160 \mathrm{O} \mathrm{C}$, the maximum power density can reach $0.61 \mathrm{~W} \mathrm{~cm}^{-2}$, and the current density at $0.6 \mathrm{~V}$ is up to $0.38 \mathrm{~A} \mathrm{~cm}^{-2}$, with $\mathrm{H}$ /air and a platinum loading of $0.5 \mathrm{mg} \mathrm{cm}^{-2}$ on both electrodes. The MEA with the GDEs shows good stability for fuel cell operating in a short term durability test.
\end{abstract}

\section{Introduction}

In recent years, high temperature proton exchange membrane fuel cells (PEMFCs) based on phosphoric acid (PA)-doped polybenzimidazole (PBI) electrolyte, which are capable of operating at temperatures above $120{ }^{\circ} \mathrm{C}$, have attracted wide interest due to their advantages over low-temperature PEMFCs based on perfluorosulphonic acid polymer electrolytes (e.g. Nafion). These advantages include faster electrode reaction kinetics, high tolerance to $\mathrm{CO}$ in fuel hydrogen, elimination of cathode flooding and simpli- fied thermal management [1,2]. In particular, high temperature operation eliminates the need for a humidification unit, which is quite attractive for vehicles equipped with PEMFCs. However, the sluggish kinetics of the oxygen reduction reaction (ORR) [3] and the transport limitations of protons and reactants in cathode, especially in the presence of PA, limit the cell performance of the high temperature PEMFC. 
Therefore, enhancing the cell performance of high temperature PEMFC is one of the most important issues for being more widely considered as an alternative to the low temperature PEMFC systems.

Membrane electrode assembly (MEA) is the core component of PEMFC and electrochemical reaction only takes place at 'triple-phase boundaries', where reactant, electrolyte and electrons are brought together. It consists of a proton exchange membrane sandwiched between two gas diffusion electrodes (GDEs), which possess a porous structure that allows easy transport of reactant gases and water to and from the catalytically active zone. Therefore, the fabrication of GDE has significant influence on the performance of high temperature PEMFC. It is expected that the optimization of GDE, either on component, structure, or preparation method, will make improvements on the cell performance. For example, Lobato et al. respectively investigated the influence of the $\mathrm{PBIeH}_{3} \mathrm{PO}_{4}$ in the electrode structure [4], platinum percentage on the carbon support of commercial catalyst [5], carbon content in the micro- porous layer (MPL) [6] and catalytic ink preparation method [7] on the performance of high temperature PBI fuel cells. Seland et al. [8] studied the single cell performance of PBI fuel cell by varying the platinum content in the Pt/C catalyst and catalyst loading, as well as the loading of the PBI electrolyte dispersed in the catalyst layer (CL) in order to determine the optimum structure of their anodes and cathodes. Pan et al. [9] investigated the porosity of GDEs the fuel cell performance by introducing porogens such as ammonium oxalate, carbonate and acetate or acid-soluble oxide, e.g. ZnO into the supporting layer and/or CLs. Their results demonstrated that an increase in the overall electrode porosity from $38 \%$ to $59 \%$ was achieved without sacrificing the catalytic activity of the electrodes. By performing fuel cell tests, significant effects of the electrode porosity were observed on the cathodic limiting current density and air stoichiometry, anodic limiting current and hydrogen utili- zation, as well as the pressure and temperature impacts.

The binder properties and CL deposition method also play major roles in determining GDE structure and, thereby, cell performance. Park et al. [10], Mazúr et al. [11] and Mamlouk et al. $[12,13]$ individ- ually investigated the effects of several different binders, including PBI, PTFE and polyurethane, on the performance of high temperature PEMFC electrode. Their results reveal that the electrode with PBI binders did not show any improvement in cell performances. Alter- native structures based on PTFE and $\mathrm{H}_{3} \mathrm{PO}_{4}$ showed advantages over PBI-based electrodes due to higher oxygen permeability and less danger of the CL flooding by PA. Furthermore, Mazúr et al. [11] and Millington et al. [14] also investigated different techniques for GDE fabrication. They found that the spraying technique can provide a significantly more homogeneous and reproducible deposition of the CL onto the GDL, compared with other commonly used ones like brushing, doctor blade, and screen printing.

In this work, a novel spraying technique, called automatic catalyst spraying under irradiation (ACSUI), was developed to prepare the GDEs for high temperature PEMFCs. Employing PTFE as binder, a much better porous CL structure can be achieved by simultaneously evaporating the solvent during spraying, followed by sintering at elevated 
temperature. The resultant GDE was physically characterized by pore size distribution and scanning electron microscopy (SEM). Effects of PTFE binder content, PA impregnation and heat treatment on the GDEs were investigated to determine the optimum performance of the single cell. Polarization and durability test showed that the MEA using the GDEs prepared by this method has high performance and good stability for high temperature PEMFC operation.

\subsection{Literature summary of single cell performance of PA-doped PBI high temperature PEMFC}

Although many researchers reported the cell performances in their studies on PBI-based PEMFCs, most of these works were focused on developing PBI-based polymer membranes [15e18], in which neither were the MEAs optimized, nor are the membranes commercially available. For this reason, the cell performances re- ported in these works are excepted from our discussion. More representative performance data have been obtained by the different research groups using significantly different approach of electrode fabrication and performance optimization. In order to make some comparisons, some of the available results have been tabulated, as shown in Table 1. It can be seen that almost all the present MEAs for high temperature PEMFC were fabricated by catalyst coated GDL (CCG), in which either PBI or PTFE was used as the binder. PA-doped PBI and AB-PBI polymer membranes are the most commonly used PEM in these studies due to their commercial availabilities. Normally, most of these MEAs were operated at around $160{ }^{\circ} \mathrm{C}$ and ambient pressure, with the Pt loadings of wo.5 $\mathrm{mg} \mathrm{cm}^{-2}$ on both anode and cathode.

The literature cell performances are typically around $0.23 \mathrm{e} 0.52 \mathrm{~A} \mathrm{~cm}^{-2}$ at the working voltage of $0.6 \mathrm{~V}$, and the maximum power densities of $0.3 e 0.63 \mathrm{~W} \mathrm{~cm}-2$ can be reached at $0.3 \mathrm{~V}$ or $0.35 \mathrm{~V}$ when pure oxygen was used as the oxidant. From the point of view of commercialization and real applications, usage of air is more practical to operate PEM fuel cells. When air was used, however these values are typically below $0.2 \mathrm{~A} \mathrm{~cm}^{-2}$ and $0.3 \mathrm{~W} \mathrm{~cm}^{-2}$, respectively. Only a few results published with the current densities at $0.6 \mathrm{~V}$ above $0.2 \mathrm{~A} \mathrm{~cm}^{-2}$ and the maximum power densities over $0.3 \mathrm{~W} \mathrm{~cm}^{-2}$. The excellent results of wo.36 $\mathrm{A} \mathrm{cm}^{-2}$ and wo.53 $\mathrm{W} \mathrm{cm}^{-2}$ from Matar et al. [24] and Zhang et al. [25] seem only possible due to the use of commercial MEAs with relatively high Pt loading of total $1.7 \mathrm{mg} \mathrm{cm}^{-2}$. Reaching stable cell performance of above $0.2 \mathrm{~A} \mathrm{~cm}^{-2}$ at $0.6 \mathrm{~V}$ and maximum power density of above $0.3 \mathrm{~W}$ $\mathrm{cm}^{-2}$ under the usual operating conditions (w160 ${ }^{\circ} \mathrm{C}$, Pt loading of wo.5 $\mathrm{mg} \mathrm{cm}^{-2}$, $\mathrm{H}_{2}$ /Air, ambient pressure) is therefore considered as a significant achievement. 
Summary of literature single cell performances of PA-doped PBI high temperature PEMFC.

\begin{tabular}{|c|c|c|c|c|c|c|c|}
\hline Reference & PEM & Reactants & $\begin{array}{l}\text { Cell } \\
\text { Temp. }\left({ }^{\circ} \mathrm{C}\right)\end{array}$ & $\begin{array}{l}\text { Pt loading }\left(\mathrm{mg} \mathrm{cm}^{-2}\right) \\
\text { Anode, cathode }\end{array}$ & $\begin{array}{l}\text { Current density } \\
\text { at } 0.6 \mathrm{~V}\left(\mathrm{~A} \mathrm{~cm}^{-2}\right)\end{array}$ & $\begin{array}{l}\text { Maximum power } \\
\text { density }\left(\mathrm{W} \mathrm{cm}^{-2}\right)\end{array}$ & MEA type \\
\hline Lobato et al. [7] & PBI & $\mathrm{H}_{2} / \mathrm{O}_{2}$ & 150 & $0.5,0.5$ & $\sim 0.23$ & $\sim 0.47$ at $0.35 \mathrm{~V}$ & CCG, PBI binder \\
\hline Seland et al. [8] & PBI & $\mathrm{H}_{2} / \mathrm{O}_{2}$ & 175 & $0.4-0.6,0.4-0.6$ & $\sim 0.32$ & $\sim 0.57$ at $0.3 \mathrm{~V}$ & CCG,PBI binder \\
\hline Kim et al. [19] & AB-PBI & $\mathrm{H}_{2} / \mathrm{O}_{2}$ & 150 & $0.4,0.55$ & $\sim 0.1$ & $\sim 0.32$ at $0.35 \mathrm{~V}$ & CCG, PBI binder \\
\hline Kongstein et al. [20] & PBI & $\mathrm{H}_{2} / \mathrm{O}_{2}$ & 175 & $0.4,0.6$ & $\sim 0.32$ & 0.56 at $0.3 \mathrm{~V}$ & CCG, PBI binder \\
\hline Ong et al. [21] & AB-PBI & $\mathrm{H}_{2} / \mathrm{O}_{2}$ & 160 & $0.5,0.5$ & $\sim 0.28$ & $\sim 0.43$ at $0.35 \mathrm{~V}$ & CCG, PBI binder \\
\hline Mazúr [11] & AB-PBI & $\mathrm{H}_{2} / \mathrm{O}_{2}$ & 160 & $0.5,0.5$ & $\sim 0.42$ & $\mathrm{n} / \mathrm{a}$ & CCG, PTFE binder \\
\hline Jung et al. [22] & AB-PBI & $\mathrm{H}_{2} / \mathrm{O}_{2}$ & 150 & $0.75,0.75$ & 0.26 & $\sim 0.3$ at $0.3 \mathrm{~V}$ & CCG, PBI binder \\
\hline Pan et al. [9] & PBI & $\begin{array}{l}\mathrm{H}_{2} / \mathrm{O}_{2} \\
\mathrm{H}_{2} / \text { Air }\end{array}$ & 200 & $0.5,0.5$ & $\begin{array}{l}\sim 0.52 \\
\sim 0.18\end{array}$ & $\begin{array}{l}\sim 0.63 \text { at } 0.35 \mathrm{~V} \\
\sim 0.26 \text { at } 0.3 \mathrm{~V}\end{array}$ & CCG, PBI binder \\
\hline Lobato et al. [4] & PBI & $\begin{array}{l}\mathrm{H}_{2} / \mathrm{O}_{2} \\
\mathrm{H}_{2} / \text { Air }\end{array}$ & 125 & $0.5,0.5$ & $\begin{array}{l}\sim 0.39 \\
\sim 0.14\end{array}$ & $\begin{array}{l}\sim 0.54 \text { at } 0.35 \mathrm{~V} \\
0.3 \text { at } 0.3 \mathrm{~V}\end{array}$ & CCG, PBI binder \\
\hline Mamlouk et al. [12] & PBI & $\mathrm{H}_{2} /$ Air & 175 & $0.4,0.4$ & $\sim 0.15$ & $\sim 0.32$ at $0.35 \mathrm{~V}$ & CCG,PTFE binder \\
\hline Wannek et al. [23] & AB-PBI & $\mathrm{H}_{2} /$ Air & 160 & $0.8-1.2,0.8-1.2$ & $\sim 0.22$ & $\sim 0.28$ at $0.35 \mathrm{~V}$ & CCG, PTFE binder \\
\hline Matar et al. [24] & PBI & $\mathrm{H}_{2} /$ Air & 160 & 1.7 (Total) & $\sim 0.36$ & $\sim 0.53$ at $0.35 \mathrm{~V}$ & Commercial MEA \\
\hline Zhang et al. [25] & PBI & $\mathrm{H}_{2} / \mathrm{Air}$ & 160 & 1.7 (Total) & $\sim 0.36$ & $\sim 0.48$ at $0.35 \mathrm{~V}$ & Commercial MEA \\
\hline
\end{tabular}

\section{Experimental}

\subsection{Preparation of catalyst ink and fabrication of GDEs}

The catalyst ink was prepared by dispersing catalyst power into a mixture of isopropanol and PTFE dispersion (6o wt.\%, Aldrich). The catalyst used for both anode and cathode layers was Hispec $4000 \mathrm{Pt} / \mathrm{C}$ catalyst (40 wt.\% Pt, Johnson Matthey). The dispersion mixture was ultrasonicated for 40 min before being used. An automatic spraying machine (Nordson ASYMTEK, USA) was employed to deposit catalyst powder onto the microporous layer of a commercially available GDL (H2315-CX196, Freudenberg, Germany) to achieve a reproducible spraying pattern and CL structure/ porosity for both anode and cathode. Instead of using hot air for drying CL after ink spraying, the machine was modified to equip with five infrared lamps ( $150 \mathrm{~W}$ for each one, Philips) for simultaneously evaporating the solvent during spraying, as shown in Fig. 1. Normally, the GDEs were prepared with the dimensions of $10 \mathrm{~cm} \times 10 \mathrm{~cm}$, then it was cut into small pieces $(2.3 \mathrm{~cm} \times 2.3 \mathrm{~cm})$ for fuel cell testing and structural characterizations. The GDEs prepared by this method are denoted as GDE-1. For comparison, some GDEs were prepared by same procedure except without illumination (hot air drying after spraying), which are denoted as GDE-2. The catalyst loadings were calculated by weighing the GDEs before applying the catalyst inks, and then after application and oven drying at $80^{\circ} \mathrm{C}$ for overnight, followed by sintering at 350 ${ }^{\circ} \mathrm{C}$ for $30 \mathrm{~min}$ in $\mathrm{N}_{2}$ atmosphere. The platinum loadings of all GDEs (both anode and cathode) used for this study are $0.5 \mathrm{mg} \mathrm{cm}^{-2}$, unless otherwise stated.

Impregnation of the CLs with predefined amounts of PA was carried out by pipetting a mixture of PA and ethanol (1:6 by volume) onto the top of the GDEs in three stages at intervals of $60 \mathrm{~min}$. Afterward the GDEs were left overnight at $70{ }^{\circ} \mathrm{C}$ in an oven to evaporate ethanol and to obtain uniform acid distribution.

\subsection{Physical characterization of the GDEs}

Pore size distribution was determined by using a Tristar 3000 Surface Area and Porosity Analyzer (Micromeritics Instrument Corp. USA). An ultra-high resolution field-emission SEM (Nova ${ }^{\mathrm{TM}}$ NanoSEM 230, FEI, USA) was employed to observe the porous microstructure of the GDEs and the cross-sections of the MEAs. The cross sections for SEM

\section{http://repository.uwc.ac.za}


analysis were prepared by freezing the samples in liquid nitrogen and cutting the samples with a razor. Samples prepared by this method are reported to yield higher quality cross-sections than other methods [26].

\subsection{MEA and single cell test}

The membranes used in this study are AB-PBI (poly(2,5- benzimidazole), which were supplied by FuMA-Tech (fumapem ${ }^{\circledR}$ AM, w30 mm). For doping with PA, the membranes were immersed in $85 \%$ acid solution for $24 \mathrm{~h}$ at $85^{\circ} \mathrm{C}$, which gave the membrane an acid doping level of about 3.8 molecules of $\mathrm{H}_{3} \mathrm{PO}_{4}$ per polymer repeating unit (PRU). Before being used, the membrane was taken from the PA bath, and the superficial acid onto the membrane was thoroughly wiped off with lab tissue. The thickness of the acid doped membrane is about $80( \pm 5) \mathrm{mm}$.

Together with gaskets made of fluorinated polymer, the MEA was assembled by sandwiching the doped membrane between two GDEs impregnated with PA in a single cell fixture (BalticFuelCells GmbH, Germany) without a preceding hot-pressing step. The cell fixture consists of two graphite plates with serpentine channels. Electrical heaters and a thermocouple were embedded into the plates and connected to a Cell Compression Unit (Pragma In- dustries, France), which controlled the cell temperature at $160{ }^{\circ} \mathrm{C}$ and the piston pressure at $2 \mathrm{~N} \mathrm{~mm}^{-2}$ in this study.

The cells were operated in a FuelCon Evaluator C test station (FuelCon, Germany). Pure hydrogen was fed to the anode and air to the cathode respectively, with flow rates of $200 \mathrm{ml}$ $\mathrm{min}^{-1}$ (hydrogen) and $1000 \mathrm{ml} \mathrm{min}^{-1}$ (air), at ambient pressure. Both hydrogen and air were used as dry gases, directly from the compressed bottles without external humidification. Prior to the recording of the polarization curves, the MEAs were activated by operating the unit cell at a constant voltage (0.55 V) under the cell temperature of 160 ${ }^{\circ} \mathrm{C}$ until a stable performance was obtained. The current voltage polarization curves were obtained by measuring the current density with the stepwise decrement of voltage from 0.9 to $0.2 \mathrm{~V}$, with an interval of $0.05 \mathrm{~V}$. At each cell voltage, the current was measured after a hold time of 5 min to allow the cell approaching steady state.

\subsection{Electrochemical measurements}

Electrochemical impedance spectroscopy (EIS) and cyclic voltammetry (CV) were performed using an Autolab PGSTAT 30 Potentiostat/Galvanostat (Metrohm) equipped with a 10 A booster and a frequency response analysis (FRA) module. Because anode polarization is negligible against to cathode polarization during fuel cell operation, so the anode can be used as the counter electrode and reference electrode. The measurements were carried out at a cell voltage of $0.6 \mathrm{~V}$ with an amplitude of $5 \mathrm{mV}$, and in the frequency range of $100 \mathrm{mHze} 100 \mathrm{kHz}$. The impedance data were obtained by calculation and simulation with Autolab Nova software. Voltammetric measurements, undertaken to study the electrochemical active surface area (EASA), were conducted using dry $\mathrm{N}_{2}$ at the 
cathode (working electrode) and dry $\mathrm{H}_{2}$ at the anode (counter electrode and reference electrode) at room temperature (w25 $\left.{ }^{\circ} \mathrm{C}\right)$. Cyclic voltammogram were recorded from 1.2 $\mathrm{V}$ to $0.05 \mathrm{~V}$ at a scan rate of $0.05 \mathrm{~V} \mathrm{~s}$.

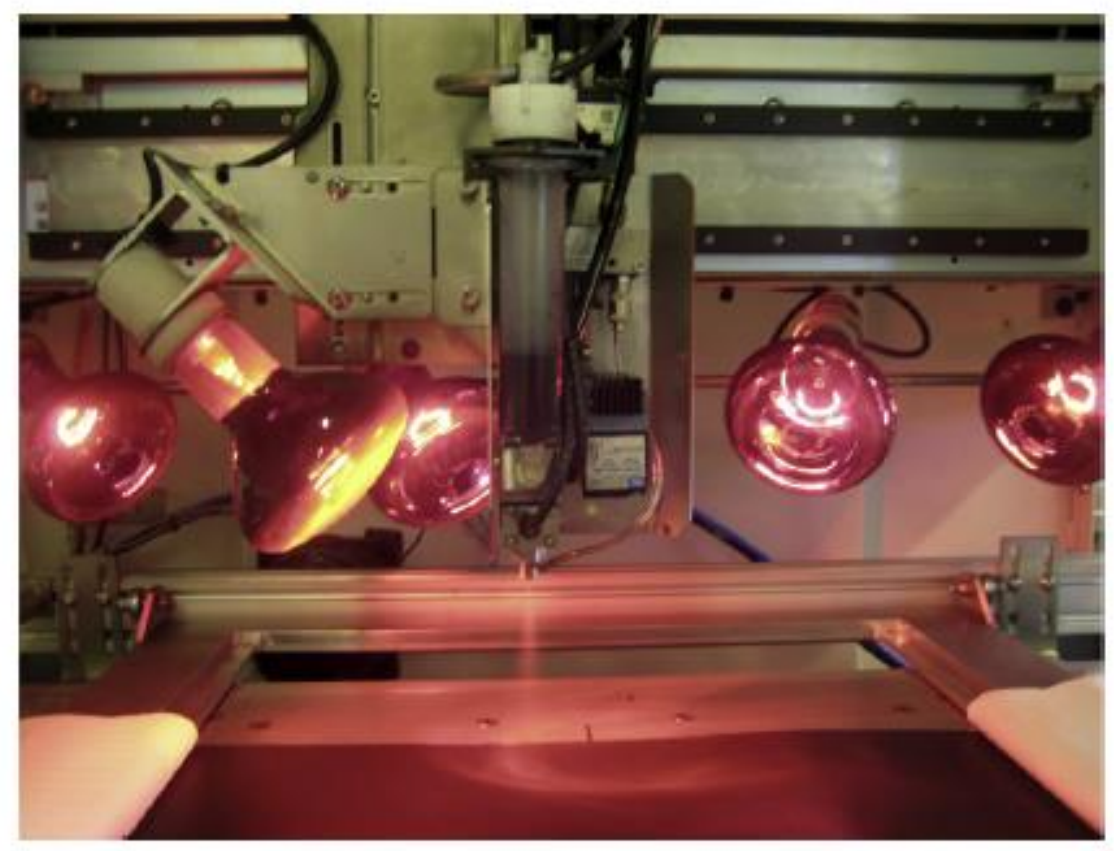

Fig. 1. GDE prepared by automatic catalyst spraying under irradiation technique.

\section{Results and discussion}

\subsection{Structural analysis}

The distribution of pore sizes is an important parameter to a GDE since the reactant gases and water (liquid or vapor) transport are regulated by the specific volumes of small and large pores [27]. The results obtained for the pore size distributions of the GDEs prepared by different procedure are shown in Fig. 2. Only the range of $0.005 \mathrm{e} 10 \mathrm{~mm}$ is measured, assuming that any larger pore size is due to the carbon support [28]. According to Watanabe et al. [29], there exist two distinctive pore distributions in the CL with a boundary of about $0.1 \mathrm{~mm}$. The primary pore is identified with the space in and between the primary particles in the agglomerates, and the secondary pore, between the agglomerates. From Fig. 2 , the main differences are observed in the range of $0.03 \mathrm{eo.7} \mathrm{mm}$, where the specific volume of the pores is greater in the GDE prepared by ACSUI method (GDE-1) as evaluated from the area. This means there exist more primary pores and secondary pores in the CL of GDE-1 than that in GDE-2. In the case of gas transport to the catalyst sites, the main contribution to gas transport is due to Knudsen diffusion in the primary pores and a molecular diffusion mechanism in the secondary pores [27]. Therefore, the larger volume of the pores in GDE-1 would make more catalyst surface available.

Fig. 3 shows the SEM images of the GDEs prepared with and without irradiation. Obviously, the surface morphology of the GDE prepared with irradiation (Fig. 3(a)) is very different with that of the one prepared without irradiation (Fig. 3(d)). By spraying catalyst 
ink under infrared lamps, the solvent (isopropanol and water) in the ink can be simultaneously evaporated, which causes bumps and agglomerates of catalyst particles with a diameter of about $30 \mathrm{e} 40 \mathrm{~mm}$ on the surface of the CL (see Fig. 3(a)), while cracks (5e $20 \mathrm{~mm}$ ) and thin crevices exist in the CL fabricated without irradiation (see Fig. 3(d)) due to the lengthening of the drying time. Although the catalyst bumps and agglomerates make the CL surface uneven, it does not seems to be a problem for interface contact with PBI membrane due to the pliability of PA-doped membrane and the considerable assembly pressure when the MEA was assembled, which can be substantiated by the MEA crosssection SEM photographs shown later (See Fig. 12, Section 3.6). However, the catalyst eventually ending up in the cracks will be far from the membrane, leading to a poor utilization, which illustrates the importance of minimizing the total crack volume in the CL $[11,20,30]$.

Fig. 3(b) and (e) show the pore structure of the CLs of the GDEs prepared with and without irradiation, respectively. It can be seen that both the GDEs have porous CL structure, but the catalyst particles of the electrode prepared under irradiation (GDE-1) seem more uniform and less big-sized agglomerates when compared to the electrode made without irradiation, which would justify the larger volume of primary pores and secondary pores in the CL of GDE-1 (See Fig. 2).

Fig. 3(c) and (f) are back-scattered electrons images of the two electrodes, which were taken to show the Pt distribution in CLs because heavy compounds like Pt shines up in SEM back-scattered mode. From them, it can be discerned that the GDE prepared under irradiation shows a more homogeneous Pt distribution when compared to the electrode prepared by spraying without irradiation, which may be attributable to the less motility of the catalyst particles in the CL during spraying because of the instantaneous evaporation of the solvent in the catalyst slurry under irradiation. Better catalyst utilization would be expected due to the homogeneous CL structure and Pt distribution of this electrode.

\subsection{Single cell performance}

Fig. 4 shows the performance comparison of the single cell with the two different GDEs. It should be noted that both GDEs used for this comparison have been structurally optimized, which is given separately in Sections 3.3 and 3.4. From Fig. 4, it is clear that the GDE prepared by catalyst spraying under irradiation method (GDE-1) yields much better performance than the MEA prepared without irradiation (GDE-2) in all regions of the polarization curve. At a working voltage of $0.6 \mathrm{~V}$, the current density of the MEA with GDE-1 reaches $0.379 \mathrm{~A} \mathrm{~cm}^{-2}, 84.9 \%$ higher than that $\left(0.205 \mathrm{~A} \mathrm{~cm}^{-2}\right)$ of the MEA with GDE-2. The maximum power density of the MEA with GDE-1 can reach $0.61 \mathrm{~W} \mathrm{~cm}^{-2}$ at $0.35 \mathrm{~V}$. These values are among the best results yet reported for similar PA-doped PBI fuel cell and operated using air, which are totally comparable to the performances of the commercial MEAs with high Pt loading (See Table 1). 
To understand the excellent performance of the GDE prepared by ACSUI method, an overall analysis on the polarization curves and electrochemical measurements on both GDEs are performed. Generally, the polarization curve of a PEMFC could be divided into three segments (corresponding to different electrochemical processes) according to its different voltage drop rates. The initial drop of the curve at a very low current density is due to the sluggish kinetics of oxygen reduction at the cathode, determined by the nature of the electrodes. It can be seen in Fig. 4 that GDE-1 shows minor voltage drop than does GDE-2 at this region (oeo.2 $\mathrm{A} \mathrm{cm}^{-2}$ ), which means the structure of GDE-1 is more effective to enhance the kinetics of ORR than that of GDE-2. This is mainly attributable to the instantaneous evaporation of the solvent during GDE-1 fabrication, which makes a more uniform CL structure and Pt distribution (as shown in Fig. 3), then making the electrochemical reactions in the CL more efficient than that in GDE-2.

The kinetic overpotential in cathode is known to be the largest overpotential in PA-doped PBI fuel cell. The low oxygen solubility and high ORR Tafel slope of $120 \mathrm{mV}$ decade $^{-1}$ in PA [3] along with anion adsorption of $\mathrm{H}_{3} \mathrm{PO}_{4}$ on Pt [31] are reported to cause slow ORR on Pt in cathode. Therefore, the superior porous structure and Pt distribution in GDE-1, which result in abundant triple-phase boundaries in the CL, are considered as the most important rea- sons for the excellent performance of GDE-1. To prove this point, CV measurements are performed to study the EASAs of the two GDEs, as shown in Fig. 5. The corresponding EASAs are calculated from the $\mathrm{H}_{2}$ desorption peak of each voltammogram and the results are also summarized in Fig. 5. The EASA of GDE-1 is about $37.4 \mathrm{~m}^{2} \mathrm{~g}^{-1}$, about $58.5 \%$ higher than that of GDE-2 $\left(23.6 \mathrm{~m}^{2} \mathrm{~g}^{-1}\right)$. This is reasonable because the CL structure of GDE-1 is more uniform and less agglomerate, which makes more Pt surface available than GDE-2 did. The EASA results are certainly consistent with their performances presented in Fig. 4.

The subsequent drop in the polarization curve is ascribed to ohmic loss, which originates from ionic flow through the electrolyte membrane, and from electron flow through the electrode layers, current collectors and flow field plates. 


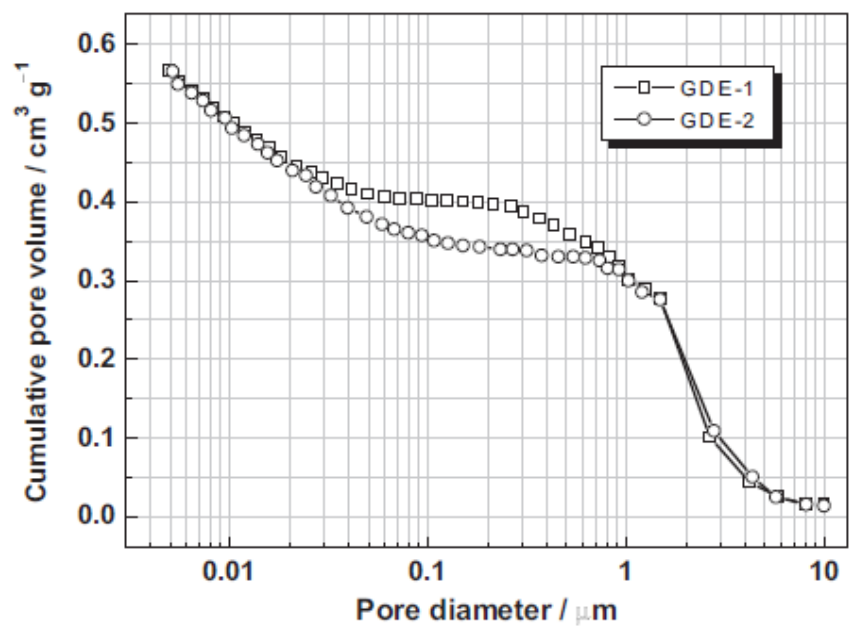

Fig. 2. Cumulative pore volume distribution of the GDEs prepared by catalyst spraying under irradiation (GDE-1) and without irradiation (GDE-2).
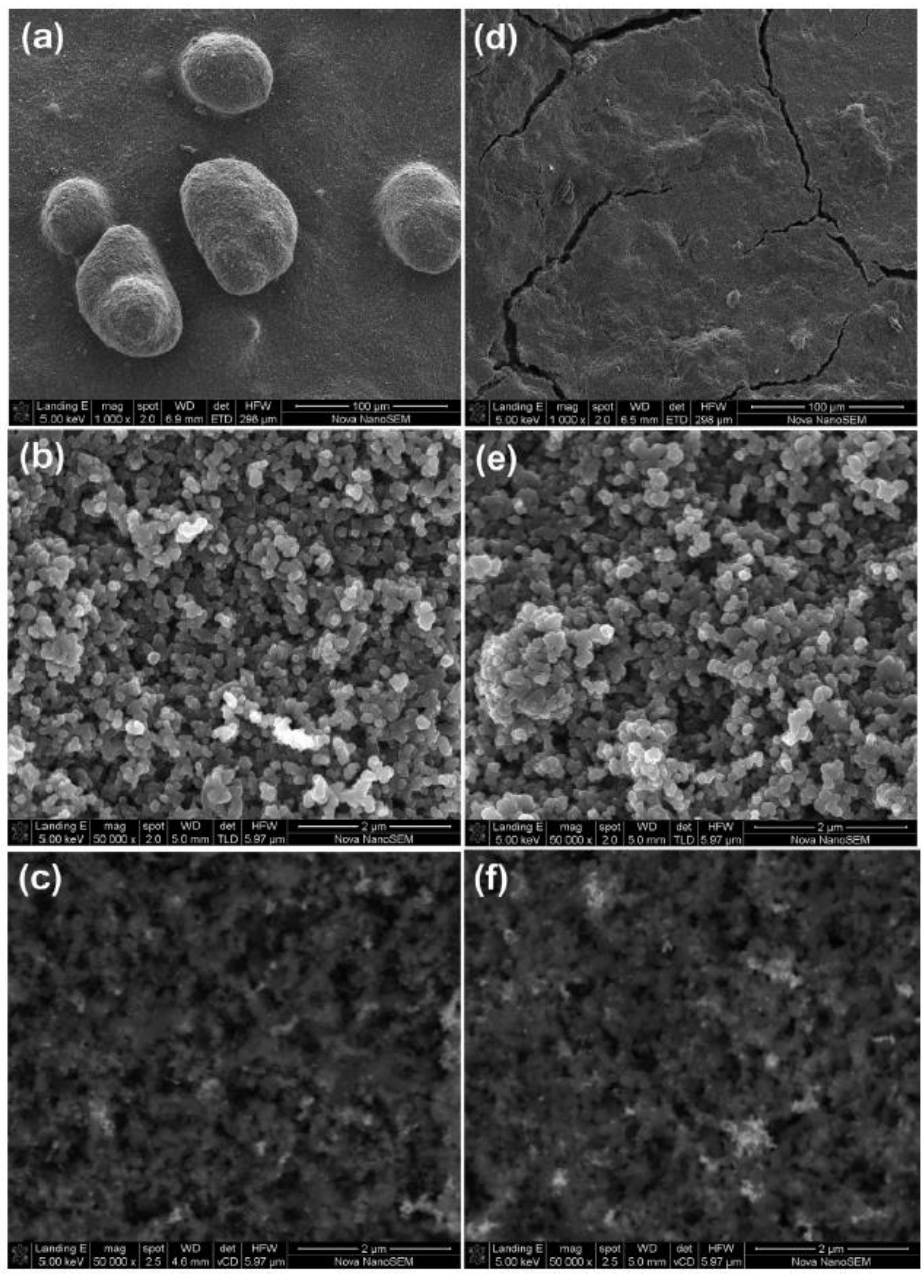

Fig. 3. SEM images of the GDEs prepared by spraying under irradiation to show (a) surface morphology, (b) porous structure and (c) Pt distribution; by spraying without irradiation to show (d) surface morphology, (e) porous structure and (f) Pt distribution. The images (c) and (f) were taken in back-scattered mode.

As shown in Fig. 4, the two MEAs present similar decreasing slopes in the linear region, implying that they had similar ohmic cell resistances. It is reasonable because

\section{http://repository.uwc.ac.za}


both GDEs were fabricated with the same catalyst loading and PTFE content, and also tested in the same fixture. To verify the resistances of the single cells with the two GDEs, in situ impedance measurements are performed at the cell voltage of $0.6 \mathrm{~V}$, as shown in Fig. 6. Only one semicircular loop can be observed in the Nyquist plot as the electrode process is dominated by ORR [32]. Through simulation with a simple equivalent circuit, their corresponding cell resistances (Rs) and charge transfer resistances (Rp) can be calculated, which are also presented in Fig. 6.

It can be seen that there is no significant difference in cell ohmic resistance for the single cell with the two GDEs, which is consistent with the similar decreasing slopes in the linear regions of the polarization curves presented in Fig. 4. However, the charge transfer resistance of GDE-1 is much smaller than that of GDE-2, which suggests that GDE-1 yielded a more efficient electrochemical active layer. The superior CL porous structure and better Pt distribution of GDE-1 can keep a high Pt utilization, and improve the charge transfer in the CL simultaneously, which makes the electrochemical process in the CL more efficient.

The last voltage drop at high current density is due to mass transport limitations occurring in the electrodes and the mem- brane. However, from Fig. 4 it can be seen that, for both GDEs, the voltage drop rates in the high current density region ( $>1.5 \mathrm{~A}$ $\mathrm{cm}^{-2}$ ) of their polarization curves are almost same with that in their linear regions, which means that no obvious mass transfer limitations in both GDEs even at the high current densities. It is understandable when considering the high operating temperature $\left(160^{\circ} \mathrm{C}\right.$, only water vapor existed in the GDEs), the porous structures, as well as the highly hydrophobic CLs and GDLs resulting from the use of PTFE.

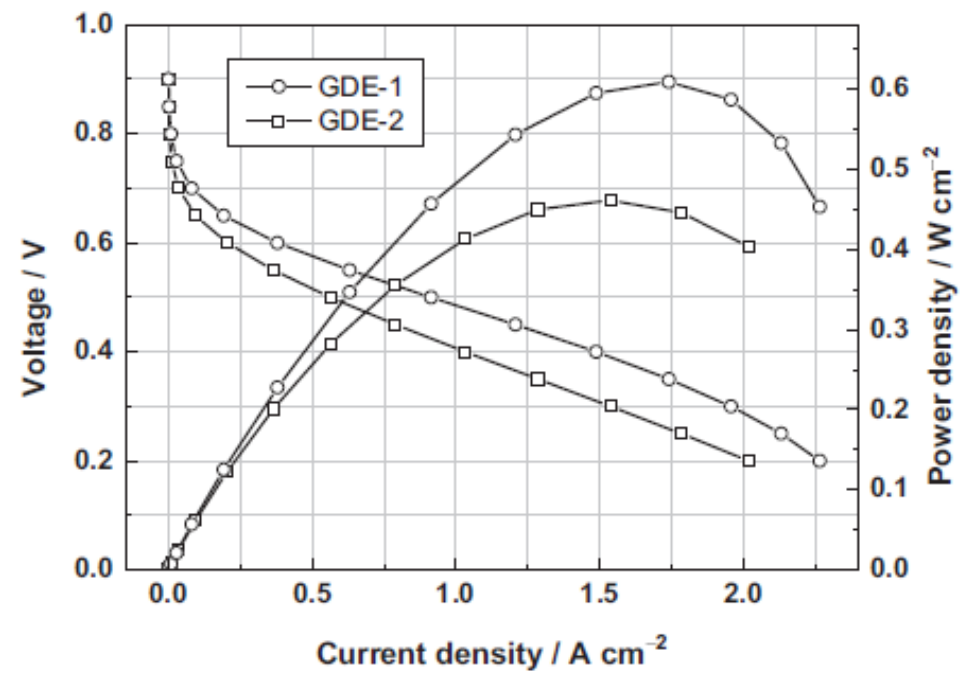

Fig. 4. Polarization curves and power density curves of PA-doped PBl fuel cell using GDEs prepared by catalyst spraying under irradiation (GDE-1) and without irradiation (GDE-2), operated at atmosphere pressure and $160^{\circ} \mathrm{C}$. 
Therefore, the transport of water in the whole GDEs could be balanced easily. Transport of reactants $\left(\mathrm{H}_{2}\right.$ and air) in the CLs can be enhanced since no flooding problem in the electrodes [33]. Furthermore, the elimination of liquid water also can increase the exposed surface area of the electrocatalysts and improve the ability of the reactants to diffuse into the reaction layers [34]. These could be the reasons why both GDEs reached their maximum power densities in this low cell voltage region ( $0.35 \mathrm{~V}$ and $0.3 \mathrm{~V}$, respectively), which also can be observed in many researchers' works (see Table 1).

From all these analysis and electrochemical results, it can be concluded that the excellent performance of GDE-1 is primarily attributable to the superior CL structure resulting from the ACSUI method, which makes a more efficient electrochemical active layer, accordingly the minor kinetic overpotential and charge transfer resistance.

\subsection{Effect of PTFE content in the CL on the MEA performance}

Although PBI is considered a good candidate for membrane materials due to its low gas permeability, the use of PBI in the CL for proton transport could impose mass transport limitation on the cell performances, depending on the thickness of the film formed on the catalyst sites [35]. Alternative CL structure based on PTFE and PA has recently been suggested by some researchers [10e13] due to the higher oxygen permeability and less danger of PA flooding in the CL than that in PBI-based electrodes. PTFE is introduced in the CL to act as binder, which can enhance porosity of the CL and provide an amorphous phase to hold the PA. Additionally, it facilitates transport of oxygen in the CL due to its hydrophobic proper- ties. In this study, $15 \mathrm{e} 50$ wt.\% of PTFE in the CLs were investigated for the optimization of the single cell performance with the GDEs prepared by automatic catalyst spraying under irradiation method. Fig. 7(a) shows the performances of the single cell using the GDEs with different PTFE content in their CLs. It should be mentioned that all these GDEs are optimized by PA impregnation in the CLs (See Section 3.4) to reach their optimal performances showed in Fig. 7. For comparison, we plot the current densities at $0.6 \mathrm{~V}$ and the maximum power densities of these MEAs, as shown in Fig. 7(b). It can be seen that the low PTFE content (15 wt.\%) in the CL is not sufficient to achieve the best fuel cell performance as this MEA only delivers $0.461 \mathrm{~W} \mathrm{~cm}^{-2}$ as the peak power density and $0.205 \mathrm{~A} \mathrm{~cm}^{-2}$ at $0.6 \mathrm{~V}$ (Fig. 7(b)). Only with a higher PTFE content, such as 25 wt.\% or 30 wt.\%, excellent cell performance is achieved with the current density above $0.33 \mathrm{~A} \mathrm{~cm}^{-2}$ at $0.6 \mathrm{~V}$, and the peak power density is above $0.56 \mathrm{~W} \mathrm{~cm}^{-2}$. Actually, from our standard fuel cell characterization $\left(160{ }^{\circ} \mathrm{C}, \mathrm{H}_{2}\right.$ /air, ambient pressure), no any important differences can be observed among the polarization curves measured with the GDEs containing 25e40 wt.\% PTFE. This means there is a minimum amount of PTFE in the electrodes that gave satisfactory performance for PBI-base high temperature fuel cell, which also can be observed in some researchers' works [12,36]. However, the GDE with 50 wt.\% PTFE performed significantly less satisfactorily (Fig. 7(a)). This could be attributed to a partial encapsulation of catalyst particles by the high volume fraction of PTFE or by the formation of non-active parts of the cell area due to large agglomerates of inert PTFE, which further 
lead to a higher cell resistance due to less ionic and electronic conductivity. From Fig. 7, the GDE with 30 wt.\% PTFE, which performed best at an usual working voltage of $0.6 \mathrm{~V}$ and maximum power density, is chose for all subsequent studies.

\subsection{Effect of PA impregnation in the GDEs on the MEA performance}

In the case of the high temperature PEMFC, phosphoric acid soaked into the porous structure is assumed to play a key role in the proton conductivity of the CL [37].

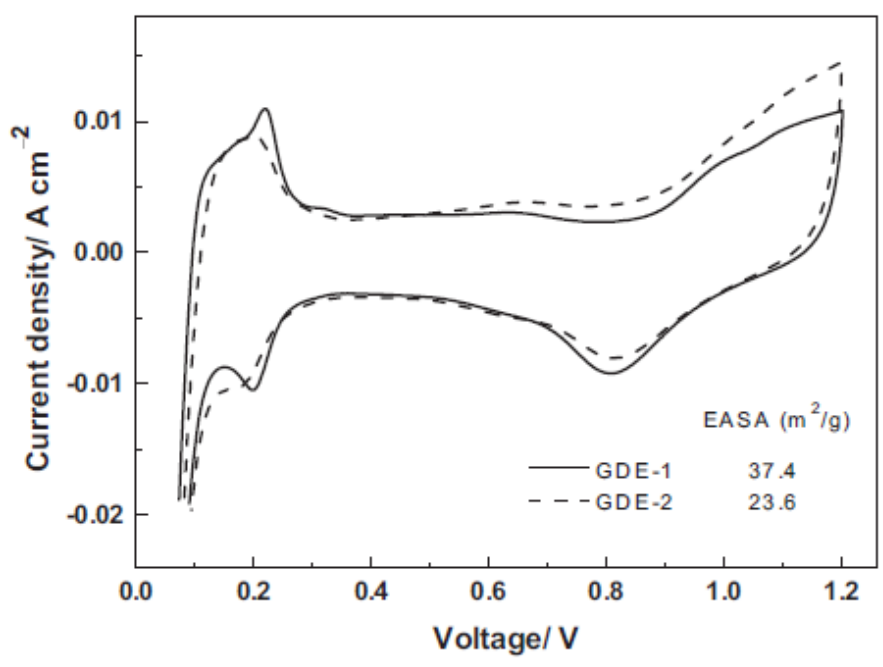

Fig 5. Cyclic voltammograms of the MEAs using GDE-1 and GDE-2.

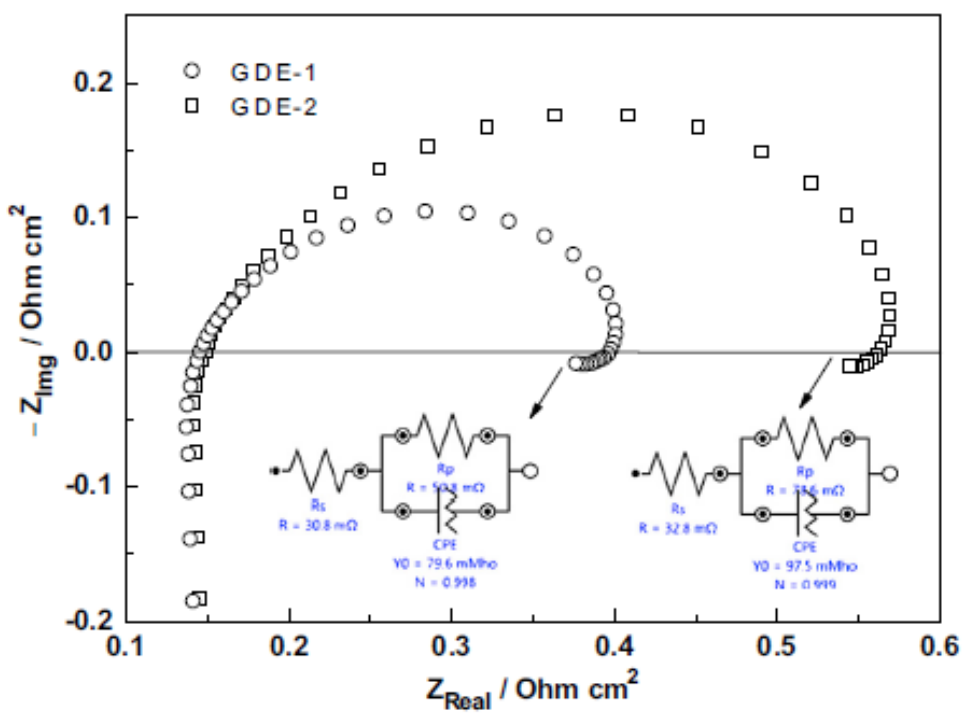

Fig. 6. In situ impedance curves of the MEAs using GDE-1 and GDE-2, at a cell voltage of $0.6 \mathrm{~V}$. 

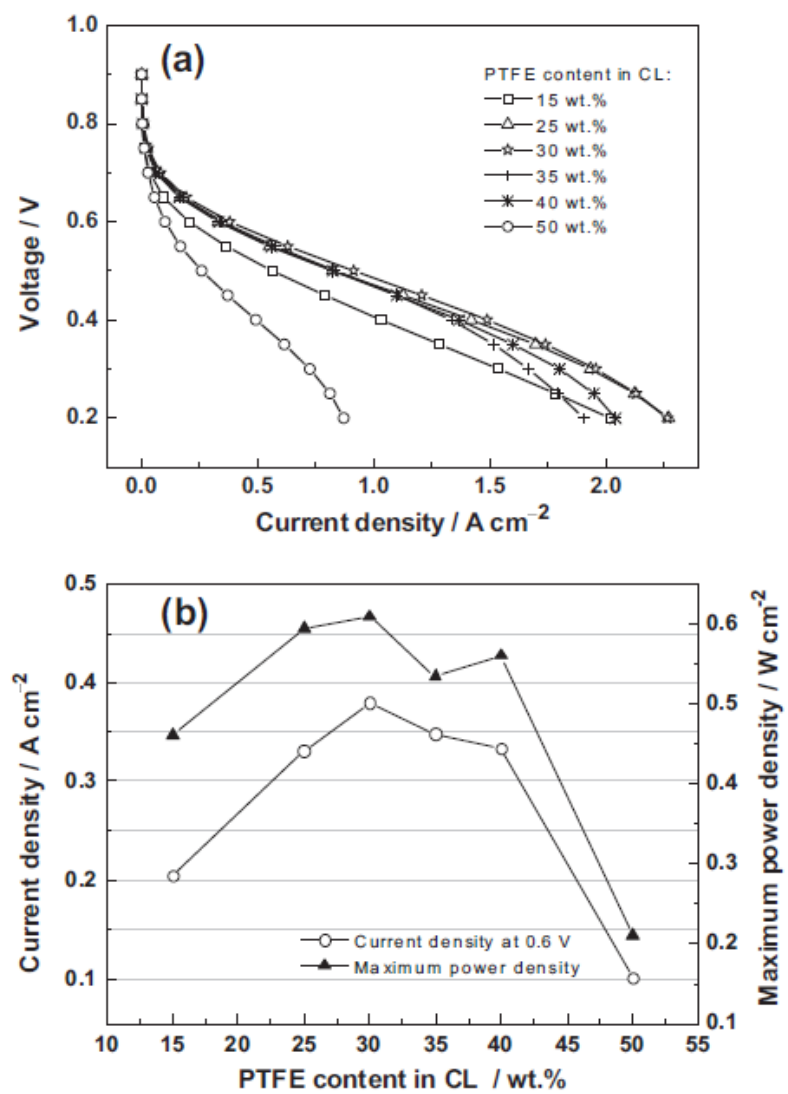

Fig. 7. The performances of single cells operate at $160^{\circ} \mathrm{C}$ and ambient pressure, using GDEs with various PTFE contents in the CLs. (a) Polarization curves corresponding to GDEs with various PTFE contents. (b) Current density at $0.6 \mathrm{~V}$ and maximum power density versus the PTFE content in CL.
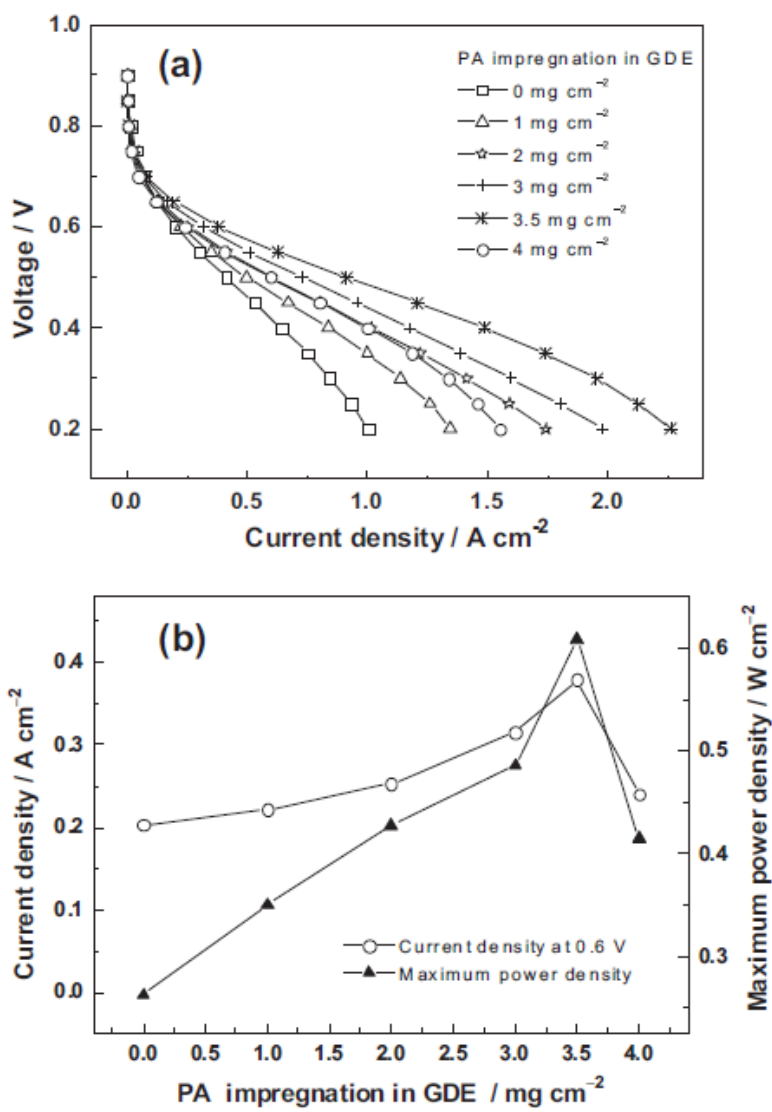

Fig. 8. The performances of single cells operate at $160^{\circ} \mathrm{C}$ and ambient pressure, using GDEs with various PA impregnations. (a) Polarization curves corresponding to GDEs with various PA impregnations. (b) Current density at $0.6 \mathrm{~V}$ and maximum power density versus the impregnation amount of PA in the GDEs.

However, liquid PA in the CLs also makes the gas transport difficult and impedes the electrode reactions by phosphate anion adsorption on the platinum catalyst, especially in the cathode due to the sluggish ORR [36]. Therefore, PA impregnation in the CL needs to be optimized using precise control mechanisms to achieve the best balance among these influencing factors and thereby obtain high cell performance. Although it is found that the dependence of cell performance on PA content in the anode is not as pronounced as for the cathode $[12,35]$, but the general tendency that excess- or insufficient PA content in the electrodes causes the performance degradation does apply to the anode. Furthermore, there exists a dynamic exchange of PA be- tween the membrane and the CLs [35,37] when the MEA is operated. For these reasons, we simply impregnated both GDEs for the cathode and the anode with same amount of PA, to find out the optimal value for the whole MEA performance, as shown in Fig. 8. Fig. 8(a) presents the polarization curves of the MEAs using the GDEs (with the optimal PTFE content in CL) impregnated with different PA loadings. For comparison purposes, we plot the current densities at $0.6 \mathrm{~V}$ and the maximum power densities of these MEAs, as shown in Fig. 8(b). It is clear that the performances of the MEAs increase with the increase of the PA content in the GDEs from o mg cm${ }^{-2}$ up to $3.5 \mathrm{mg} \mathrm{cm}^{-2}$, i.e. the current density increases from $0.203 \mathrm{~A} \mathrm{~cm}^{-2}$ to $0.379 \mathrm{~A} \mathrm{~cm}^{-2}$ at $0.6 \mathrm{~V}$, the maximum power density increases from 0.263 
$\mathrm{W} \mathrm{cm}-2$ to $0.609 \mathrm{~W} \mathrm{~cm}^{-2}$. However, further increase in the PA content to $4 \mathrm{mg} \mathrm{cm}^{-2}$ causes deteriorated performance as illustrated by the decreased current densities from $0.379 \mathrm{~A} \mathrm{~cm}^{-2}$ to $0.24 \mathrm{~A} \mathrm{~cm}^{-2}$ at the same cell voltage, with the decreased maximum power density from $0.609 \mathrm{~W} \mathrm{~cm}-2$ to $0.415 \mathrm{~W} \mathrm{~cm}^{-2}$, which indicates that higher PA amount in GDE is disadvantageous as most of the pores of the CL become filled with liquid, resulting in significant performance degradation at high current densities (Fig. 8(a)) due to the serious mass transport limitations of the reactants.

It should be pointed out that the optimal PA loading in the GDE slightly varies with the PTFE content in the CL $\left(3.5 \mathrm{mg} \mathrm{cm}^{-2}\right.$ PA impregnation only for the optimal PTFE content of 30 wt.\%). Based on our experiments, the optimal value is about $3 \mathrm{mg} \mathrm{cm}^{-2}$ for the GDEs with lower PTFE content (15e25 wt.\%), 3.5e4 $\mathrm{mg} \mathrm{cm}^{-2}$ for the higher PTFE content (not detailed here), which is thought to be affected by the change in the thickness and structure of the CL [23,35]. In contrast, the MEA without PA impregnation in the GDEs shows the poorest fuel cell performance under the same operating conditions (Fig. 8). This explicitly indicates that PA impregnation is necessary for the high performance of the MEA with the "PTFE- based" GDEs.

\subsection{Effect of the heat treatment of the GDEs on the single cell performance}

Some researchers report that heat treatment (sintering at $350^{\circ} \mathrm{C}$ ) of the PTFEbonded electrodes to increase hydrophobicity has negative effect on improving the cell performance as this limits the mobility of PA in the CLs [12].

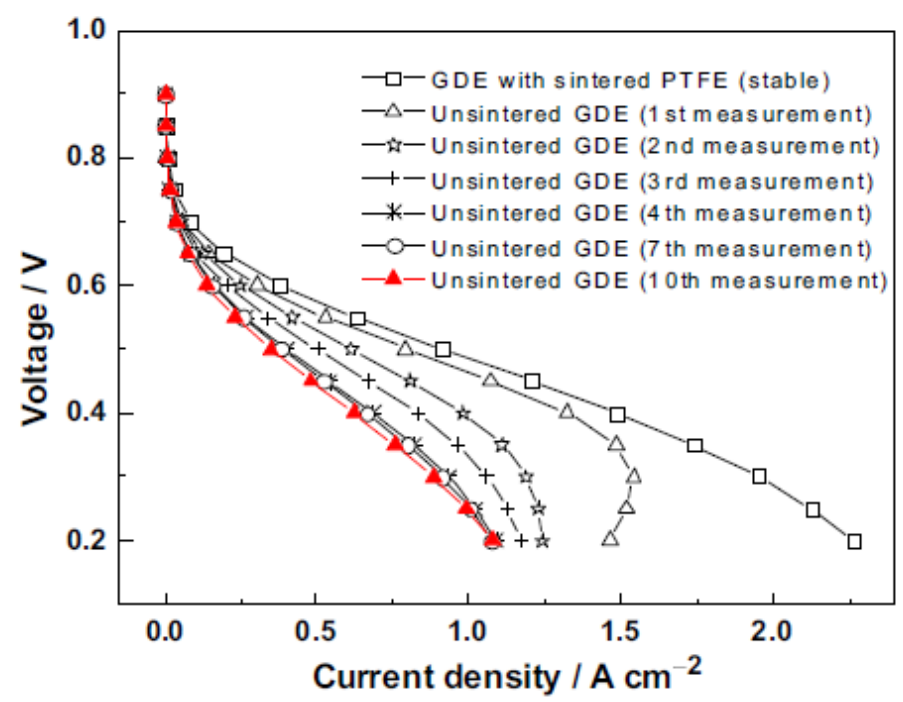

Fig 9. Heat treatment effect of the GDEs with 30 wt.\% PTFE content in the CL on the single cell performance.

For this consideration, a contrast test on the MEAs with the sintered GDEs and the unsintered GDEs was conducted to confirm this effect on our GDEs. The result is

\section{http://repository.uwc.ac.za}


shown in Fig. 9. On the contrary, heat treatment delivers a high and stable cell performance for the MEA with our GDEs, while the performance of the MEA with unsintered GDEs is poor and quite unstable in initial hours of test, especially at high current densities. This could be due to that the unsintered PFTE polymer particles are agglomerated in the CL (without the formation of network), resulting in reduced CL porosity and gas permeability, as well as increased possibility of PA flooding. This is documented by the back-scattered electrons image shown in Fig. 10(b), in which the PTFE agglomerates can be observed notably. As the same figure shows, in the case of the sintered GDE (Fig. 10(a)), the structure of the resulting CL is more homogeneous and porous.

These two opposite results may arise from the different means of introducing PA into the CLs. In some researchers' works [12,35], the GDEs were tested without preimpregnation of PA, so the proton transfer in the CLs purely relies on the mobile acid from the PA-doped membrane. In this case, the heat-treated GDEs exhibit a high degree of hydrophobicity repelling any mobile acid coming from the membrane. Therefore, the PA amounts in the CLs are low, resulting in limited active three-phase zone close to the membrane boundary, whereas the remainders of the CLs remain relatively inactive. This could be even worse for the membrane with low PA doping level. However, in our case, the GDEs were pre-impregnated with the suitable PA amount before being tested, so the conductivities of the CLs less rely on the mobile acid from the membrane, instead the membrane can keep a high acid doping level due to the high hydrophobic PTFE network repelling the mobile PA from the membrane. Moreover, the high hydrophobic PTFE network can hold the impregnated PA in the CLs, thereby reducing the leaching of PA, accordingly the performance stability of the MEA could be enhanced. For these reasons, heat treatment is thought to be necessary for the good and stable performance of the MEA with the PA-impregnated GDEs.

\subsection{Stability of the MEA performance}

The stability or durability of MEA is a major concern for the real application and commercialization of fuel cells. The remarkable long term stability of PA-doped PBI MEA was achieved in some research groups' works [38e41]. To verify the stability of the MEA with our GDEs, a short term durability test was performed at $160^{\circ} \mathrm{C}$ and $0.2 \mathrm{~A}$ $\mathrm{cm}^{-2}$, as shown in Fig. 11. The test started with a $105 \mathrm{~h}$ continuous operation, then followed a $175 \mathrm{~h}$ intermittent operation with three complete shut downs (cooled to room temperature, no gases flow) to simulate the fuel cell system shutdown and restarting that is likely to occur in actual system operation. It is note that the cell voltage quickly reached stable in less than $4 \mathrm{~h}$ (small insert in Fig. 11), which is believed to be one of the advantages of the PTFE-based electrodes over the conventional PBI-based electrodes [12], as the latter normally require days even weeks of activation in order to achieve the best operating conditions $[8,22,42]$. 


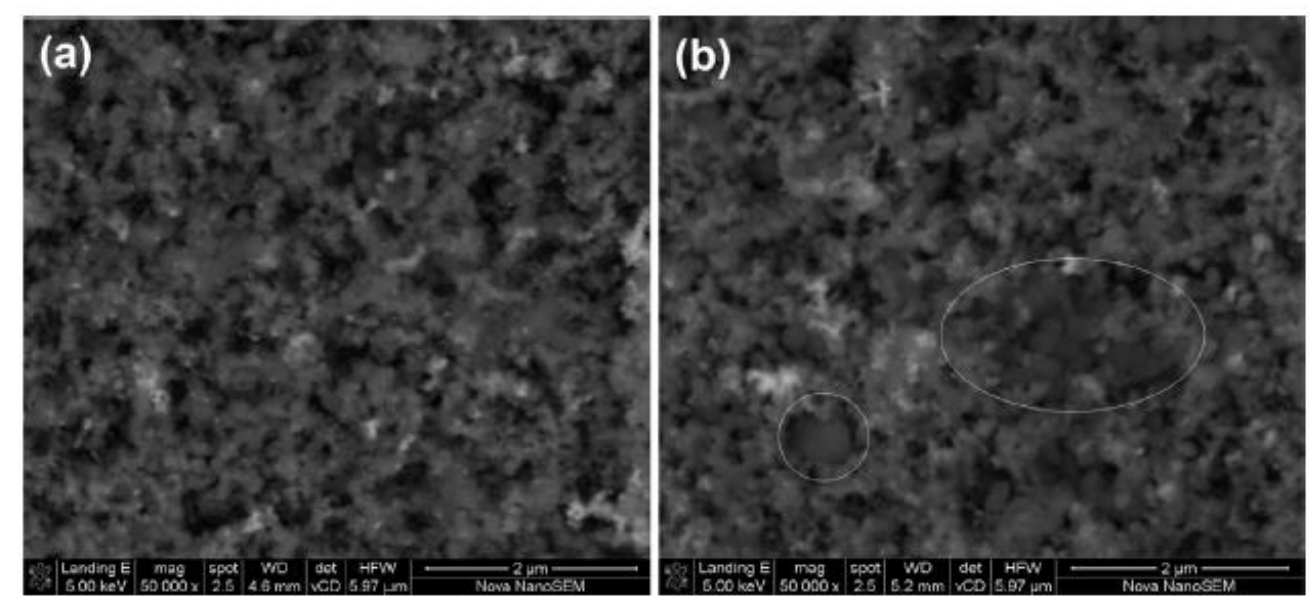

Fig. 10. Back-scattered electrons images showing the CL structure of (a) the sintered GDE, and (b) the unsintered GDE.

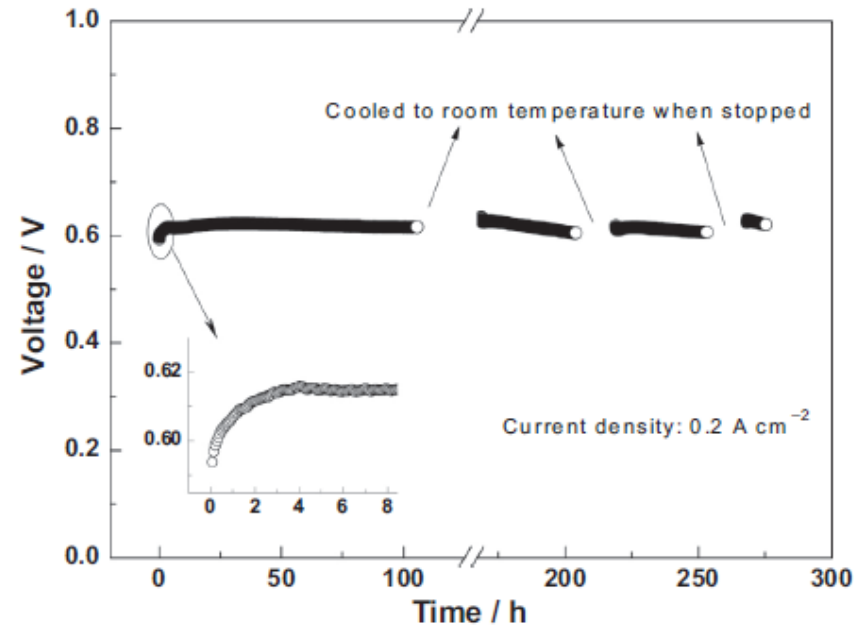

Fig 11. Stability of the MEA performance with the optimized GDEs during $275 \mathrm{~h}(105 \mathrm{~h}$ continuous and $170 \mathrm{~h}$ intermittent) fuel cell operating at $160{ }^{\circ} \mathrm{C}$ and $0.2 \mathrm{~A} \mathrm{~cm}^{-2}$.
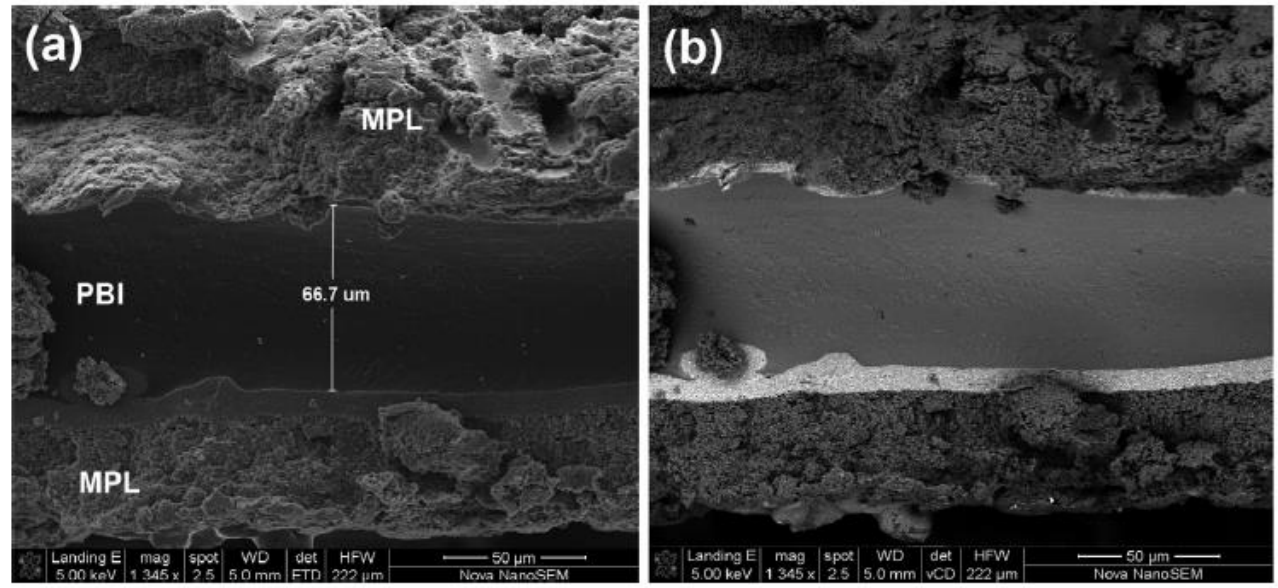

Fig. 12. SEM images of the cross-section of the MEA after durability test. (a) SEM scans in normal mode; (b) SEM scans in back-scattered mode. 
It is mainly because the conductivity of PA and the oxygen diffusion in PA are an order of magnitude higher than that for PA-doped PBI [43], so pre-impregnating the GDEs with PA reduces the time needed before the MEA reaches its best performance.

After the activation, the cell voltage of the MEA remains at w0.62 V without obvious drop after the $275 \mathrm{~h}$ operation. Usually, the PA loss from the PA-doped PBI membrane and the GDEs is speculated as a major degradation mechanism of the PBI-based high temperature PEM fuel cell during short term operation [41]. The combination of high cell temperature and high load conditions (i.e., high water generation) leads to a proposed steam distillation mechanism for PA removal from the MEA [41]. Therefore, the good stability of our MEA performance implies that the GDEs provide a good structure to keep required PA in the membrane and the CLs, resulting in a very low PA loss rates under the operating conditions. The degradation rate calculated by linear fitting of cell voltage data points after the MEA activation is about $17.2 \mathrm{mV} \mathrm{h}^{-1}$, which is among the values reported in other researchers' works (normally 4.9e 25 $\left.\mathrm{mV} \mathrm{h}^{-1}\right)[38,41,44,45]$.

A post-analysis using SEM on the cross-section of the MEA after the durability test shows in Fig. 12. In order to get high quality cross-section, the carbon papers were peeled off when the sample was prepared. It can be seen that the PBI membrane remains a considerable thickness of about $66.7 \mathrm{~mm}$ (the original thickness (PAdoped) is about $80 \mathrm{~mm}$, cell compression may reduce it greatly), which suggests that the membrane still keeps a high PA doping level after the durability test [39]. In addition, it can be seen that although the CL surface is not even, an intimate contact is still formed between the CLs and the PBI membrane, which can be observed more clearly in the back-scattered electrons image (Fig. 12(b)). The bumps and agglomerates of catalyst particles even increased the contact area between the CLs and the membrane, which could make better catalyst utilization. From all these results, we believe that the good performance and stability of the MEA benefits from the intimate contact between the CLs and the PBI membrane, the unique surface morphology, as well as the superior porous structure of the GDEs prepared by ACSUI method.

\section{Conclusions}

High performance MEA with the GDEs prepared by a novel ACSUI method has been developed for PA-doped PBI high temperature PEMFC. Under an usual operating conditions $\left(160^{\circ} \mathrm{C}, \mathrm{H}_{2}\right.$ /Air, ambient pressure), the peak power density of the single cell reached $0.61 \mathrm{~W}$ $\mathrm{cm}^{-2}$, and the current density at $0.6 \mathrm{~V}$ was up to $0.38 \mathrm{~A} \mathrm{~cm}^{-2}$, which are comparable to the best results yet reported for similar MEAs with Pt loading of wo. $5 \mathrm{mg} \mathrm{cm}^{-2}$. It is found that the PTFE content in the CLs and the PA impregnation in the GDEs are important to achieve suitable cell performance. A relatively high PFTE content (25e40 wt.\%) gave satisfactory cell performances. Heat treatment of the PTFE-based GDEs is thought to be necessary for the good and stable performance of the MEA. The MEA showed good stability

\section{http://repository.uwc.ac.za}


in a short term operation: the cell voltage remained at wo.62 V without obvious drop after the $275 \mathrm{~h}$ operation. It concludes that the good performance and stability of the MEA benefits from the intimate contact between the CLs and the PBI membrane, the unique surface morphology, as well as the superior porous structure of the GDEs prepared by ACSUI method.

\section{Acknowledgments}

This work is supported by Hydrogen and Fuel Cell Technologies RDI Programme (HySA), funded by the Department of Science and Technology in South Africa (project KP1-So1). 


\section{References}

[1] N.L. Garland, J.P. Kopasz, J. Power Sources 172 (2007) 94 e99.

[2] S.J. Peighambardoust, S. Rowshanzamir, M. Amjadi, Int. J. Hydrogen Energy 35 (2010) 9349e9384.

[3] K.L. Hsueh, E. Gonzalez, S. Srinivasan, D.T. Chin, J. Electrochem. Soc. 131 (1984) 823e828.

[4] J. Lobato, P. Cañizares, M.A. Rodrigo, J.J. Linares, F.J. Pinar, Int. J. Hydrogen Energy 35 (2010) 1347e1355.

[5] J. Lobato, P. Cañizares, M.A. Rodrigo, J.J. Linares, D. Úbeda, F.J. Pinar, Fuel Cells 10 (2010) 312e319.

[6] J. Lobato, P. Canizares, M.A. Rodrigo, D. Ubeda, F.J. Pinar, J.J. Linares, Fuel Cells 10 (2010) $770 \mathrm{e} 777$.

[7] J. Lobato, M.A. Rodrigo, J.J. Linares, K. Scott, J. Power Sources 157 (2006) 284e292. [8] F. Seland, T. Berning, B. Børresen, R. Tunold, J. Power Sources 160 (2006) 27e36. [9] C. Pan, Q. Li, J.O. Jensen, R. He, L.N. Cleemann, M.S. Nilsson, N.J. Bjerrum,

Q. Zeng, J. Power Sources 172 (2007) 278e286.

[10] J.O. Park, K. Kwon, M.D. Cho, S.G. Hong, T.Y. Kim, D.Y. Yoo, J. Electrochem. Soc.

158 (2011) B675eB681.

[11] P. Mazúr, J. Soukup, M. Paidar, K. Bouzek, J. Appl. Electrochem. 41 (2011) 1013e1019. [12] M. Mamlouk, K. Scott, Int. J. Energy Res. 35 (2011) 507e519.

[13] M. Mamlouk, K. Scott, Int. J. Hydrogen Energy 35 (2010) 784 e793.

[14] B. Millington, V. Whipple, B.G. Pollet, J. Power Sources 196 (2011) $8500 e 8508$.

[15] Q. Li, R. He, J.O. Jensen, N.J. Bjerrum, Fuel Cells 4 (2004) $147 e 159$.

[16] Q. Li, J.O. Jensen, R.F. Savinell, N.J. Bjerrum, Prog. Polym. Sci. 34 (2009) 449e477. [17] J.A. Asensio, P. Gómez-Romero, Fuel Cells 5 (2005) 336e343.

[18] J.A. Asensio, E.M. Sanchez, P. Gomez-Romero, Chem. Soc. Rev. 39 (2010) $3210 \mathrm{e} 3239$.

[19] J.-H. Kim, H.-J. Kim, T.-H. Lim, H.-I. Lee, J. Power Sources 170 (2007) $275 \mathrm{e} 280$.

[20] O.E. Kongstein, T. Berning, B. Børresen, F. Seland, R. Tunold, Energy 32 (2007) 418e422.

[21] A.-L. Ong, G.-B. Jung, C.-C. Wu, W.-M. Yan, Int. J. Hydrogen Energy 35 (2010) 7866-7873

[22] G.-B. Jung, C.-C. Tseng, C.-C. Yeh, C.-Y. Lin, Int. J. Hydrogen Energy (2012).

[23] C. Wannek, W. Lehnert, J. Mergel, J. Power Sources 192 (2009) 258e266.

[24] S. Matar, A. Higier, H. Liu, J. Power Sources 195 (2010) $181 \mathrm{e} 184$.

[25] J. Zhang, Y. Tang, C. Song, J. Zhang, J. Power Sources 172 (2007) $163 \mathrm{e} 171$.

[26] H.-N. Su, S.-J. Liao, Y.-N. Wu, J. Power Sources 195 (2010) 3477e3480.

[27] H.-K. Lee, J.-H. Park, D.-Y. Kim, T.-H. Lee, J. Power Sources 131 (2004) $200 \mathrm{e} 206$. 
[28] J. Lobato, P. Cañizares, M. Rodrigo, C. Ruiz-López, J. Linares, J. Appl. Electro- chem. 38 (2008) $793 \mathrm{e} 802$.

[29] M. Watanabe, M. Tomikawa, S. Motoo, J. Electroanal. Chem. Interfacial Elec- trochem. 195 (1985) 81e93.

[30] D.S. Hwang, C.H. Park, S.C. Yi, Y.M. Lee, Int. J. Hydrogen Energy 36 (2011) $9876 \mathrm{e} 9885$.

[31] C. Song, Y. Tang, J.L. Zhang, J. Zhang, H. Wang, J. Shen, S. McDermid, J. $\mathrm{Li}$,

P. Kozak, Electrochim. Acta 52 (2007) 2552e2561.

[32] J.L. Jespersen, E. Schaltz, S.K. Kaer, J. Power Sources 191 (2009) 289e296. [33] Y. Shao, G. Yin, Z. Wang, Y. Gao, J. Power Sources 167 (2007) $235 \mathrm{e} 242$.

[34] W.H.J. Hogarth, J.C. Diniz da Costa, G.Q. Lu, J. Power Sources 142 (2005) $223 \mathrm{e} 237$.

[35] R. He, Q. Li, A. Bach, J.O. Jensen, N.J. Bjerrum, J. Membr. Sci. 277 (2006) 38e45. [36] C. Wannek, I. Konradi, J. Mergel, W. Lehnert, Int. J. Hydrogen Energy 34 (2009)

$9479 \mathrm{e} 9485$.

[37] Y. Oono, A. Sounai, M. Hori, J. Power Sources 189 (2009) 943e949. [38] T.J. Schmidt, J. Baurmeister, J. Power Sources 176 (2008) 428e434. [39] Y. Oono, A. Sounai, M. Hori, J. Power Sources 210 (2012) 366e373.

[40] Y. Oono, T. Fukuda, A. Sounai, M. Hori, J. Power Sources 195 (2010) 1007e1014. [41] S. Yu, L. Xiao, B.C. Benicewicz, Fuel Cells 8 (2008) $165 \mathrm{e} 174$.

[42] M. Boaventura, A. Mendes, Int. J. Hydrogen Energy 35 (2010) 11649e1166o. [43] Z. Liu, J.S. Wainright, M.H. Litt, R.F. Savinell, Electrochim. Acta 51 (2006) 3914-3923.

[44] C. Wannek, B. Kohnen, H.F. Oetjen, H. Lippert, J. Mergel, Fuel Cells 8 (2008) 87-95.

[45] A.D. Modestov, M.R. Tarasevich, V.Y. Filimonov, N.M. Zagudaeva, Electrochim. Acta 54 (2009) 7121-7127. 